BONPLANDIA 17(1): 91-92. 2008

\title{
NOTA
}

\section{BUTIA ERIOSPATHA (DRUDE) BECC., PALMERA NATURALIZADA EN EL NORTE DE MISIONES (ARGENTINA)}

\author{
ANTONIO KRAPOVICKAS ${ }^{1} \&$ MASSIMILIANO DEMATTEIS ${ }^{1}$
}

\begin{abstract}
Summary: Krapovickas, A. \& M. Dematteis. 2008. Butia eriospatha (Drude) Becc., palm naturalized in northern Misiones (Argentina). Bonplandia 17(1): 91-92. ISSN: 0524-0476.

Butia eriospatha (Drude) Becc. is cited for the first time for the flora of Argentina. This species can be distinguished from other species of the genus by its glaucous leaves and the densely tomentose spathe.
\end{abstract}

Key words: Palmeae, Butia, naturalized.

Resumen: Krapovickas, A. \& M. Dematteis. 2008. Butia eriospatha (Drude) Becc., palmera naturalizada en el norte de Misiones (Argentina). Bonplandia 17(1): 91-92. ISSN: 0524-0476.

\begin{abstract}
Butia eriospatha (Drude) Becc. es citada por primera vez para la flora de Argentina. Esta especie se diferencia de otras especies del género por las hojas glaucas y la espata densamente tomentosa.
\end{abstract}

Palabras clave: Palmeae, Butia, naturalizada.

Butia eriospatha (Drude) Becc. es una palmera característica y exclusiva de la «zona dos campos» del planalto meridional de Brasil, donde vive en Paraná, Santa Catarina y Rio Grande do Sul. Debido a su buen aspecto es frecuentemente cultivada en jardines y plazas de las principales ciudades del planalto de Santa Catarina (Reitz, 1974: 59).

Es una palmera de 3-4 m de altura fácilmente reconocible por sus hojas pinnadas, glaucas, pecíolos con espinas y por la espata de la inflorescencia con tomento castaño oscuro, denso y persistente (Fig. 1 B).

Según un poblador de Campina de América, procedente de Santa Catarina, cultivó esta palmera en su jardín y se multiplicó naturalmente en la zona. Tuvimos oportunidad de observar palmeras de distintas edades y for- mando a veces pequeños grupos de 5 ó 6 individuos (Fig. 1 A).

Esta es la primera cita de Butia eriospatha para Argentina, pues no figura en la abundante bibliografía sobre palmeras. Tampoco es citada en el Catálogo de las plantas vasculares de la República Argentina, donde Xifreda y Sanso (1996) solamente mencionan Butia yatay (Mart.) Becc. subsp. yatay y B. yatay subsp. paraguayensis (Barb. Rodr.) Xifreda \& Sanso.

Material estudiado: ARGENTINA. Misiones: Campina de América, $10 \mathrm{~km}$ E de Bernardo de Irigoyen, naturalizada, 10-III-2006, Krapovickas \& Dematteis 47926 (CTES). BRASIL. Santa Catarina: $10 \mathrm{~km}$ E de Ponte Serrada, са. 26 50 'S 52 $\mathrm{W}$, 17-II-1978, Krapovickas \& Cristóbal 33704 (CTES, F, MBM).

${ }^{1}$ Instituto de Botánica del Nordeste, Casilla de Correo 209, 3400 Corrientes, Argentina. 


\section{Bibliografía}

REITZ, B. 1974. Palmeiras. Fl. Il. Catar. PALM: 1-189.
XIFREDA, C. C. \& A. M. SANSO. 1996. Arecaceae. In F. O. Zuloaga \& O. Morrone (eds.). Catálogo de las plantas vasculares de la República Argentina, I: 104-106.
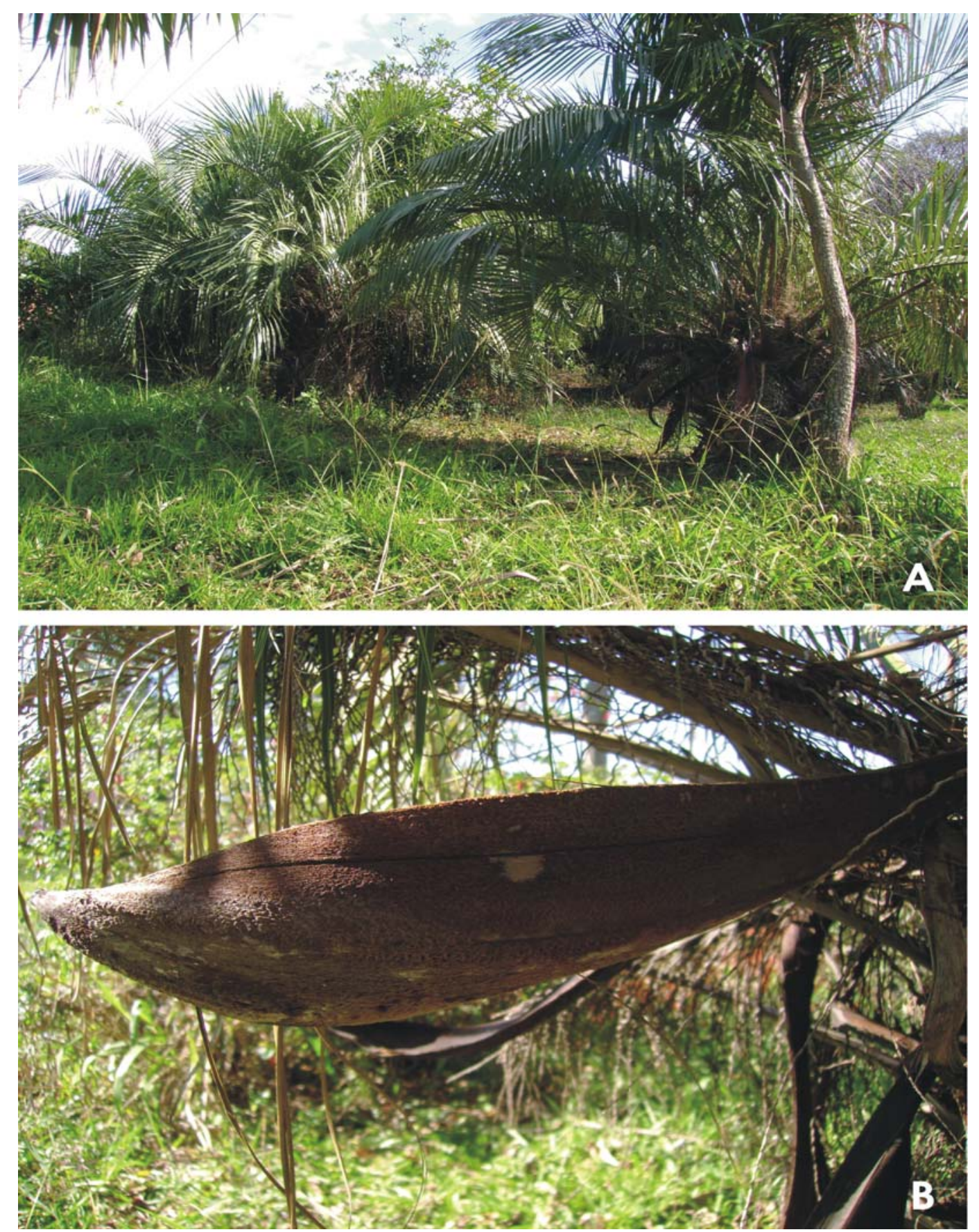

Fig. 1. Butia eriospatha. A: ejemplares adultos y B: espata.

Original recibido el 21 de marzo de 2008; aceptado el 22 de mayo de 2008. 